\title{
Article \\ Stakeholders' Perceptions on the Role of Urban Green Infrastructure in Providing Ecosystem Services for Human Well-Being
}

\author{
Mojca Nastran ${ }^{1, * \mathbb{D}}$, Marina Pintar ${ }^{2}$, Špela Železnikar $^{2}$ and Rozalija Cvejić $^{2} \mathbb{D}$ \\ 1 Department for Forestry and Renewable Forest Resources, Biotechnical Faculty, University of Ljubljana, \\ Večna Pot 83, 1000 Ljubljana, Slovenia \\ 2 Department of Agronomy, Biotechnical Faculty, University of Ljubljana, Jamnikarjeva 101, \\ 1000 Ljubljana, Slovenia; marina.pintar@bf.uni-lj.si (M.P.); spela.zeleznikar@bf.uni-lj.si (Š.Ž.); \\ rozalija.cvejic@bf.uni-lj.si (R.C.) \\ * Correspondence: mojca.nastran@bf.uni-lj.si
}

check for updates

Citation: Nastran, M.; Pintar, M.;

Železnikar, Š.; Cvejić, R. Stakeholders' Perceptions on the Role of Urban Green Infrastructure in Providing Ecosystem Services for Human Well-Being. Land 2022, 11, 299.

https://doi.org/10.3390/ land11020299

Academic Editors: Peter Mederly and Davina Vačkářová

Received: 3 February 2022

Accepted: 14 February 2022

Published: 16 February 2022

Publisher's Note: MDPI stays neutral with regard to jurisdictional claims in published maps and institutional affiliations.

Copyright: (C) 2022 by the authors. Licensee MDPI, Basel, Switzerland. This article is an open access article distributed under the terms and conditions of the Creative Commons Attribution (CC BY) license (https:// creativecommons.org/licenses/by/ $4.0 /)$.

\begin{abstract}
The perception of linkages between ecosystem services (ES) and the urban green infrastructure (UGI) is evaluated, and their impact on human well-being (WB) is defined. Using a theoretical approach, the UGI's specific contribution to WB is calculated as the sum of the products of (a) the number of perceived ES per ES group and the WB weight factor divided by the product of (b) the number of respondents and (c) the sum of the products of ES and the WB weight factor. Stakeholders demand more ES than the perceived ES supply from all types of UGI, especially for the social relations component of WB. The highest number of perceived ES and greatest impact on all WB components is provided by urban forests. This method could be helpful in acknowledging ES and involving stakeholders not previously familiar with the ES concept with the aim of introducing ES into UGI governance.
\end{abstract}

Keywords: participatory ecosystem services assessment; well-being; urban ecosystem; millennium ecosystem assessment; urban green infrastructure

\section{Introduction}

The urban green infrastructure (UGI) is "an interconnected network of urban green spaces, including multiple types of natural or man-made systems, ranging from large-scale water or terrestrial ecosystems to small-scale pocket parks or green components, such as green walls in cities" [1] (p. 5). In urban environments, people obtain from ecosystems, such as UGI, multiple benefits or, in other words, ecosystem services (ES) [2], which is increasingly recognized as a crucial factor contributing to human well-being (WB) in cities [3]. The ES of UGI are crucial for achieving the United Nations Sustainable Development Goal of good health and well-being in cities. Though the importance of ES for various WB dimensions is poorly understood [2], it is believed that UGI provides WB relevant benefits, such as basic material for a good life, health, security and effects social relations [3]. The identification of links between ecosystems and WB is important for designing ecosystem-based approaches to WB [4]. Researchers, decision makers, and planners are increasingly becoming aware of UGI and its role in ensuring ES to increase WB [5]. Ecosystem assessment can influence policy decisions to address local needs better, improve living standards, or enable more effective climate change adaptation strategies [6].

ES gained recognition with the introduction of the millennium ecosystem assessment (MEA) [3]. According to it, there are four groups of ES: supporting, provisioning, regulating, and cultural. Additionally there are five WB components: (i) basic materials for a good life represent access to resources for a viable existence, including food and building material, or income to purchase them; (ii) security, including safe access to natural and other resources, 
security of people and property, and living in predictable and controllable environments safe from natural and man-made disasters, including those resilient to environmental stress, such as drought, heat island effects, floods, and pests; (iii) health, consisting of adequate food and nutrition, disease prevention, clean and safe drinking water, a healthy physical environment, and energy for comfortable temperature control; (iv) good social relations, including social cohesion, mutual respect, good gender and family relations, the ability to help others and care for children, the realization of aesthetic and recreational values, the ability to express cultural and spiritual values, the opportunity to observe and learn from nature, the development of social capital, and the avoidance of tension and conflict over diminishing resources; and (v) freedom and choice in terms of making decisions concerning ES and WB. The different ES groups affect WB components with different intensities [3].

UGI consists of different urban ecosystems contributing to various ES; each ES group has its intensity, affecting each individual WB component. For example, the regulating ES group has a strong influence on the health and safety component of WB but a weak influence on social relations [3].

Knowledge of stakeholder perception of ES in different UGI types could serve as a basis for improving the consideration of ES in urban planning processes and strategy development. Pauleit et al. [7] claim that knowledge regarding UGI and functional linkage to ES is insufficient. Despite the well-known positive correlation between green areas and health, the causality between different types of green areas and health components is still far from being explained. Perceptions of ecosystem connections and WB value can vary from person to person and context to context, depending on the level of knowledge and benefits that people value or need [8]. Ecosystems can provide benefits to WB only for specific stakeholder groups or at specific times and places [9]. Local knowledge, the involvement of stakeholders in the planning process, and constructive science-policy dialogue are options for improving planning processes and enhancing sustainability during implementation [10]. Planning and designing solutions that integrate people's needs, WB, and the ecosystem functioning are more sustainable. Knowing ES supply and demand gaps are important for providing the $\mathrm{WB}$ of citizens [11,12]. The benefits provided depend not only on the ability of an ecosystem to provide services, but also on the demand for those services, which depends on many different factors, including cultural factors and the perceived value of the service [13]. For this reason, it is valuable to involve diverse stakeholders in ES assessment and UGI planning. At the same time, participatory ES assessment methods are also a process that raises the level of understanding of the need for the sustainable maintenance of urban ecosystems and their services. Such planning processes can be better facilitated using decision support approaches and tools [14].

There are numerous methods for assessing ES, and they differ in terms of how they involve stakeholders, whether they are qualitative or quantitative, dynamic or static, and which ES and ecosystem components they include [2,15]. Despite the various methods for mapping ES and assessing their provision and demand, there is still insufficient application in planning practice and policy formulation [16,17]. Burkhard et al. [18] claim that, in particular, the demand side of ES has not been adequately considered. Before creating a basis for incorporating the ES concept into local urban planning and further urban UGI planning with the stakeholders, we need to be cognizant of citizen perception and demand for different ES [19]. Although a growing body of literature addresses links between UGI and ES, there is still a considerable gap in exploring its effect on WB.

Based on the scoping literature review using Web of Science, we identified 105 articles, including expressions "urban green infrastructure", "ecosystem services" and "well-being", occurring in the title, abstract, author keywords, and keywords plus, with the period limitations 2022-2019. The identified articles differ in how they address the UGI and ES contribution to WB. The majority (91 articles) link UGI with ES but discuss the results in the context of WB without providing a specific quantified contribution of WB to UGI through ES and without discriminating between individual WB components. Only the remaining 14 articles offer distinct methods to explore the contribution of UGI to WB 
through ES. Approaches used in these reviewed articles focus on subjective WB, using the participatory process, personal observation, experience, social survey, questionnaire, manipulated reality, or fuzzy cognitive mapping [20-25]. Others objectivize WB evaluation using literature review, field research, spatial analysis involving GIS and remote sensing, land use, landscape metrics, statistical methods [26-31], or a combination of subjective and objective WB evaluation methods [32,33].

This article highlights the possible use of qualitative linkages between ES and WB presented in the MEA [3] to (quantitatively) assess the potential impact of UGI on WB through the perceived ES of selected UGI types within a small group of stakeholders. This approach was applied to the following:

- Identify and evaluate how stakeholders perceive ES and connect them with different types of UGI by testing the approach application on the city of Ljubljana;

- Compare current and desired levels of ES supplied by UGI in the city;

- Introduce the ES concept into one official space planning legislation document.

Not the least important aspect of applying this approach is to raise awareness of ES to create the basis for incorporating the ES concept into local urban planning and further UGI planning practice in cities. We applied the presented approach to a selected group of stakeholders in Ljubljana previously unaware of the ES concept.

The basic ES concept does not change much, but the emphasis among the elements that researchers consider in their attempts to introduce the concept into urban ecosystem planning does change: ES flows, provisions, potentials, capacity, sinks, stocks, etc. [13]. With our research, we offer the possibility of a rough and straightforward overview of ES supply and demand from the perspective of selected stakeholders and thus the chance to use the results as a starting point for UGI planning to support WB.

The most important contribution of this article with respect to others is that it quantifies the strength of the ES contribution of UGI to WB. We have not yet come across an approach in the available literature that can do this. The contribution is significant, as it allows us to relate the types of urban green areas with WB to explore planning and management options related to increasing the range and quality of ES. The most important contribution to the research field is that it uses the qualitative approach of MEA to indirectly explore how important UGI might be for WB. The identified gap between ES supply and demand helps prioritize and guide UGI planning from the policy to the management level.

\section{Methods}

\subsection{Theoretical Approach}

We analyzed the linkage between the supply and demand of selected ES provided by UGI and their influence on WB, using the approach in Figure 1. The approach uses eight types of green areas that are a part of UGI: (1) forests, (2) parks, (3) agricultural land, (4) sports areas, (5) allotment gardens, (6) degraded areas, (7) riparian vegetation, and (8) green areas within settlements. These were selected by researchers because they dominate Ljubljana's environs (types 1-4), or because of their high relevance for developing Ljubljana's city planning documents (types 5-8). The ES list and the contribution of UGI type to WB through ES was adapted from MEA [3] that defines contribution qualitatively, either as strong, medium, or weak (Figure 1).

The strength of the connection between ES and WB (weak, medium, and strong) was taken from the MEA, but is to some extent supported by the literature review. For quantitative calculation, we assigned numerical weights to these three descriptive categories ( weak $=1$, medium $=2$, and strong $=3$ ). In this way, the qualitative contribution of each UGI type to WB was quantified. The overview of the weight factors used to describe potential link intensity between ES group (provisioning, regulating, cultural) and individual WB components are shown in Table 1. The MEA approach and the assumed strengths of the linkages between ES and WB can be partially supported by the review literature, which indicates that the most frequently assessed urban ES are from the categories of regulation 
and maintenance [15,34] or provision [29], suggesting that these ES categories are perceived to have the most important impacts on WB.

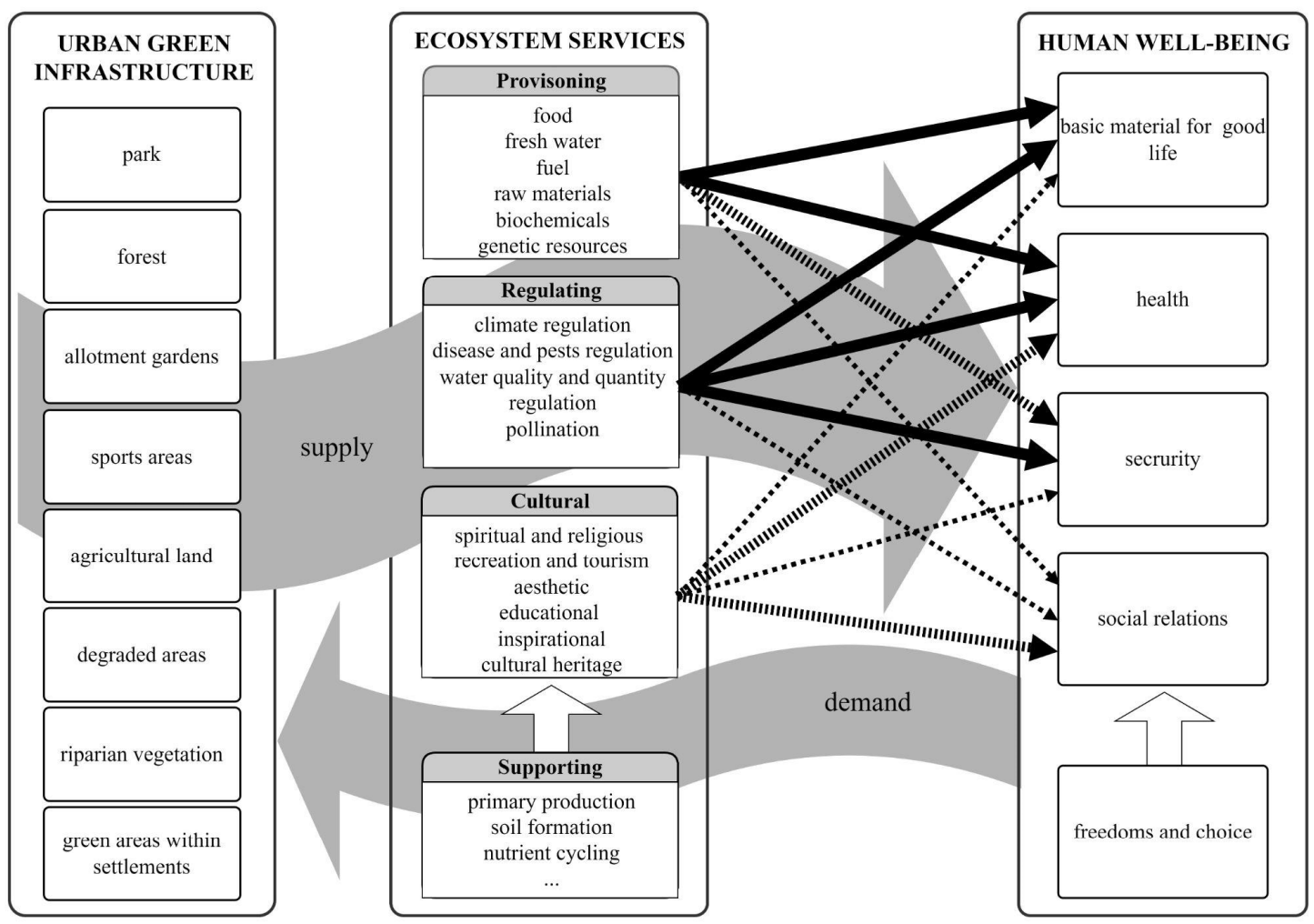

Intensity of linkages between ecosystem services and human well-being:

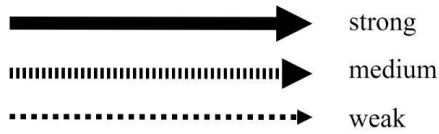

Figure 1. Linkage between ecosystem services of urban green infrastructure and human well-being (adapted from MEA [3]).

Table 1. Linkage between groups of ecosystem services (ES) and human well-being (WB) components represented by weight factor.

\begin{tabular}{ccccc}
\hline \multirow{2}{*}{ Groups of ES } & \multicolumn{4}{c}{ Human WB Component } \\
\cline { 2 - 5 } & Basic Material & Health & Security & Social Relation \\
\hline Provisioning ES $\left(\mathrm{n}_{\mathrm{P}}=6\right)$ & $\mathrm{f}_{\mathrm{s}}=3$ & $\mathrm{f}_{\mathrm{s}}=3$ & $\mathrm{f}_{\mathrm{m}}=2$ & $\mathrm{f}_{\mathrm{W}}=1$ \\
Regulating ES $\left(\mathrm{n}_{\mathrm{R}}=4\right)$ & $\mathrm{f}_{\mathrm{s}}=3$ & $\mathrm{f}_{\mathrm{s}}=3$ & $\mathrm{f}_{\mathrm{s}}=3$ & $\mathrm{f}_{\mathrm{w}}=1$ \\
Cultural ES $\left(\mathrm{n}_{\mathrm{C}}=6\right)$ & $\mathrm{f}_{\mathrm{w}}=1$ & $\mathrm{f}_{\mathrm{m}}=2$ & $\mathrm{f}_{\mathrm{w}}=1$ & $\mathrm{f}_{\mathrm{m}}=2$ \\
\hline Ab &
\end{tabular}

Abbreviations used: $f_{W}=$ weak linkage between ES group and WB component, $f_{m}=$ medium linkage between ES group and $\mathrm{WB}$ component, $\mathrm{f}_{\mathrm{s}}=$ strong linkage between $\mathrm{ES}$ group and $\mathrm{WB}$ component, $\mathrm{n}_{\mathrm{P}}=$ number of provisioning $\mathrm{ES}, \mathrm{n}_{\mathrm{R}}=$ number of regulating $\mathrm{ES}, \mathrm{n}_{\mathrm{C}}=$ number of cultural ES .

The UGI's contribution to WB is calculated as the sum of the product of (a) the number of perceived ES per ES group and WB weight factor divided by the product of (b) the number of respondents and (c) sum of the products of the number of ES and WB weight factors (Equations (1)-(4)). The UGI-specific demand contribution to human WB is calculated as the sum of (a) the UGI-specific contribution to WB and quotient between (b) the product of the demanded ES and WB weight factor divided by (c) the product of the number of respondents and sum of ES numbers and WB weight factor products; see the example for WB security demand in Equation (5). 


$$
\begin{gathered}
\text { WB basic material provision }=\left(\left(\mathrm{X}_{\mathrm{P}} \mathrm{f}_{\mathrm{s}}+\mathrm{X}_{\mathrm{R}} \mathrm{f}_{\mathrm{s}}+\mathrm{X}_{\mathrm{C}} \mathrm{f}_{\mathrm{W}}\right) / \mathrm{N}\left(\mathrm{n}_{\mathrm{P}} \mathrm{f}_{\mathrm{s}}+\mathrm{n}_{\mathrm{R}} \mathrm{f}_{\mathrm{s}}+\mathrm{n}_{\mathrm{C}} \mathrm{f}_{\mathrm{W}}\right)\right) / 100 \\
\text { WB health provision }=\left(\left(\mathrm{X}_{\mathrm{P}} \mathrm{f}_{\mathrm{s}}+\mathrm{X}_{\mathrm{R}} \mathrm{f}_{\mathrm{s}}+\mathrm{X}_{\mathrm{C}} \mathrm{f}_{\mathrm{m}}\right) / \mathrm{N}\left(\mathrm{n}_{\mathrm{P}} \mathrm{f}_{\mathrm{s}}+\mathrm{n}_{\mathrm{R}} \mathrm{f}_{\mathrm{s}}+\mathrm{n}_{C} \mathrm{f}_{\mathrm{m}}\right)\right) / 100 \\
\text { WB social relations provision }=\left(\left(\mathrm{X}_{\mathrm{P}} \mathrm{f}_{\mathrm{W}}+\mathrm{X}_{\mathrm{R}} \mathrm{f}_{\mathrm{W}}+\mathrm{X}_{\mathrm{C}} \mathrm{f}_{\mathrm{m}}\right) / \mathrm{N}\left(\mathrm{n}_{\mathrm{P}} \mathrm{f}_{\mathrm{W}}+\mathrm{n}_{\mathrm{R}} \mathrm{f}_{\mathrm{W}}+\mathrm{n}_{\mathrm{C}} \mathrm{f}_{\mathrm{m}}\right)\right) / 100
\end{gathered}
$$

$W B$ security demand $=W B$ security provision $+\left(\left(Y_{P} f_{m}+Y_{R} f_{s}+Y_{C} f_{W}\right) / N\left(n_{P} f_{m}+n_{R} f_{s}+n_{C} f_{W}\right)\right) / 100$

where

$\mathrm{X}_{\mathrm{P}}=$ number of perceived provided provisioning ES

$X_{R}=$ number of perceived provided regulating ES

$\mathrm{X}_{\mathrm{C}}=$ number of perceived provided cultural ES

$\mathrm{f}_{\mathrm{W}}=$ weak linkage between ES group and WB component

$\mathrm{f}_{\mathrm{m}}=$ medium linkage between ES group and WB component

$\mathrm{f}_{\mathrm{s}}=$ strong linkage between ES group and WB component

$\mathrm{N}=$ number of respondents

$\mathrm{n}_{\mathrm{P}}=$ number of provisioning ES

$\mathrm{n}_{\mathrm{R}}=$ number of regulating ES

$\mathrm{n}_{\mathrm{C}}=$ number of cultural ES

$\mathrm{Y}_{\mathrm{P}}=$ number of demanded provisioning $\mathrm{ES}$

$\mathrm{Y}_{\mathrm{R}}=$ number of demanded regulating ES

$\mathrm{Y}_{\mathrm{C}}=$ number of demanded cultural ES

The approach undertaken is important since most similar studies stop at the ES provision/demand and do not include WB and its components. Other studies focus only on one or two ES categories or one or two UGI categories; moreover, similar studies mainly address WB as a whole without discriminating between WB components, or focus on one of its components, mainly physical and mental health. The approach undertaken in our research article focuses on individual WB components, similar to Valente et al. [30]. However, it takes a step further in weighting the potential contribution of ES to WB compared to Valente et al. [30], who use an equal weighting approach for all WB components.

\subsection{Case Study Area}

Ljubljana (Slovenia), the European Green Capital of 2016, was selected as a study case. One of the smallest European capitals (population in 2020 ca. 300,000) has one of the highest shares of UGI (three-quarters of the city area). The strategic objective of spatial planning in the City of Ljubljana is to create an interconnected network of high-quality, multifunctional public open spaces to improve and maintain social and ecological ecosystem services [35]. The city is undergoing rapid changes concerning the urban green system. Densification, massive tourism, and the excessive use of some parts of the urban green system by city dwellers [36,37] are just some of the challenges for the management of UGI in Ljubljana. In addition, the growing number of NGO initiatives in the city dealing with the development and restructuring of green spaces shows public interest and need for high-quality green spaces [38-40]. This indicates that despite the good intentions of the city of Ljubljana and the existing development programs to promote the urban green system, the existing UGI does not fully meet the needs of the stakeholders [41,42].

\subsection{Stakeholder Engagement}

The method for the selection of stakeholders to be engaged in co-exploring links between ES, UGI and WB involved a series of workshops and stakeholder mapping exercises such as urban learning lab Matrix and Mind Maps. The selection process is described in detail by van der Jagt et al. [43]. The finally selected group of stakeholders $(\mathrm{N}=21)$ represents a diverse group of actors, from the business sector (2), local government (4), NGOs (3), research organizations (5), and young people/students (7) previously unaware of the ES concept.

The sample is not a statistically representative population of Ljubljana residents. Instead, it is a group of citizens brought together in the process of shared learning on the 
development of UGI in Ljubljana as part of the project GREEN SURGE [44]. Stakeholder engagement of the selected stakeholders was a five-year facilitated process (2014-2017). During this period, we used several events, workshops, consultations, focus groups, and team-building tools to discuss the meaning of UGI and the related ES for WB of citizens. As a result, the stakeholders actively participated in the planning, development, and governance of UGI in Ljubljana, as well as programming of city policies and strategies related to UGI and WB. A detailed description of how the network of stakeholders was established and evolved through time is presented by van der Jagt et al. [43].

The approach undertaken in our research was used as part of a one-day workshop that brought together the above stakeholders. The participants were first theoretically introduced to the ES concept and its theoretical link to UGI and WB. Next, they were asked to assign ES to individual UGI categories. Finally, participants assigned ES while discriminating between provision and demand. We considered the ES supply and demand as indicated by Burkhard et al. [45] (p. 18), where the supply of ES refers to "the capacity of a particular area to provide a specific bundle of ecosystem goods and services within a given time period" and demand of ES is "the sum of all ecosystem goods and services currently consumed or used in a particular area over a given time period." ES were divided into provision and demand functions groups for easier stakeholder understanding using the interpretation described above. Later on, ES identified by stakeholders were counted and distributed into ES group provisioning, regulating, and cultural by workshop moderators and used to apply in Equations (1)-(5).

\section{Results}

We identified how stakeholders perceive ES and connect them with different types of UGI. After summing all the attributed ES from all stakeholders by individual UGI types, the largest number of ES was assigned to forests (173) followed by agricultural land (119), allotment gardens (118), parks (114), riparian vegetation (98), green areas with settlements (86), sports areas (54), and degraded areas (33). All UGI types could contribute to the social relations component of WB more. However, forests make the largest contribution to all WB components.

We compared the current and desired levels of ES supplied by UGI in the city and defined their ES relation to WB. There is greater ES demand for the social relations component of WB than supply, as with the remaining WB components, for all UGI types. The WB component seems to be more influenced by the social than the ecological system. It means the contribution of UGI's biophysical features and functions, relative to the contribution of the other social determinants of WB, is lower for the WB component of social relations than for the other components of WB. Results indicate that stakeholders possibly relate more to cultural and regulating services than provision services. Stakeholders from research organizations and youngsters identify more ES as important than other stakeholders.

The supply and demand of ES follow the same distribution pattern across WB components for all UGI types, meaning that results are not sensitive to UGI type. For every UGI type and WB component, the number of ES demanded is higher than that of the ES supplied (Figures 2 and 3). Both supply and demand of ES are higher for the social relations component of WB for all types of UGI. 
PARKS

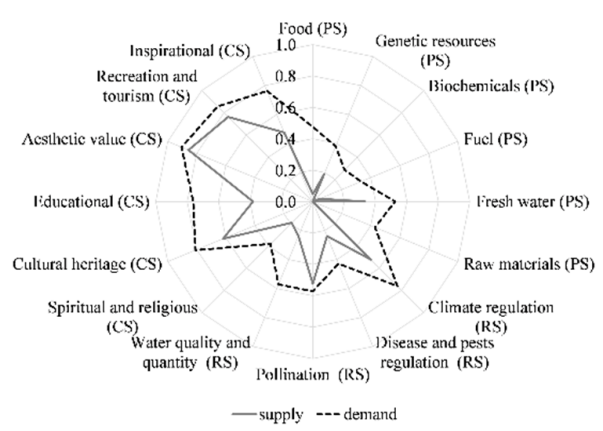

(a)

ALLOTMENT GARDENS

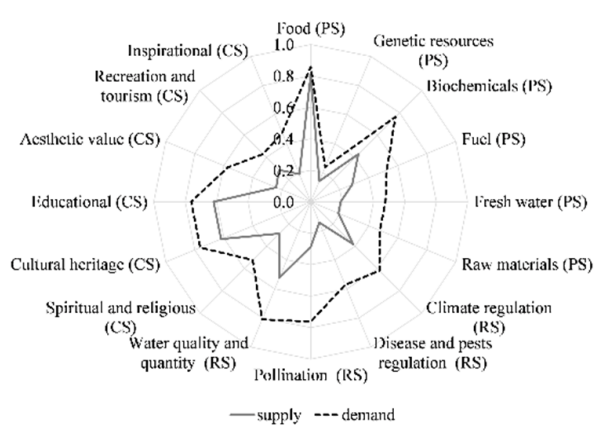

(c)

AGRICULTURAL LAND

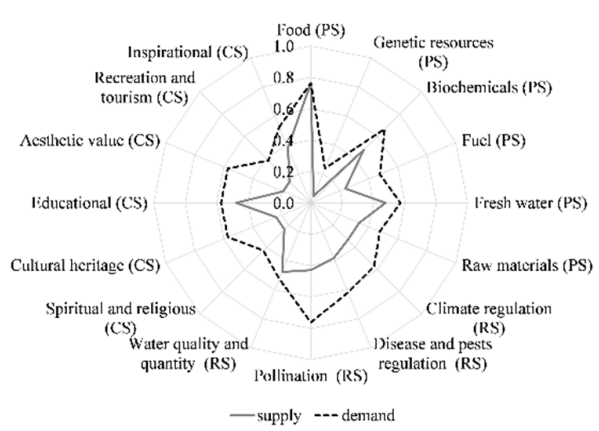

(e)

RIPARIAN VEGETATION

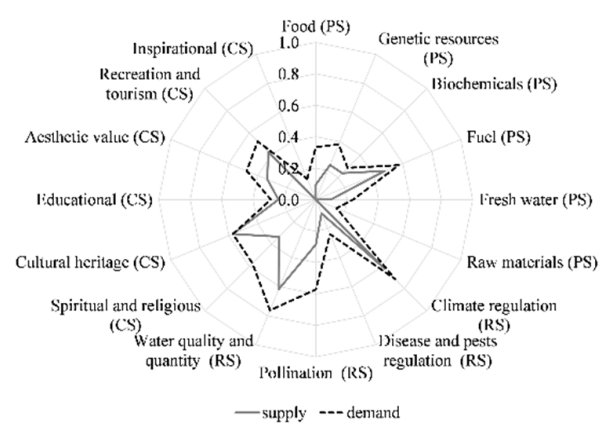

(g)

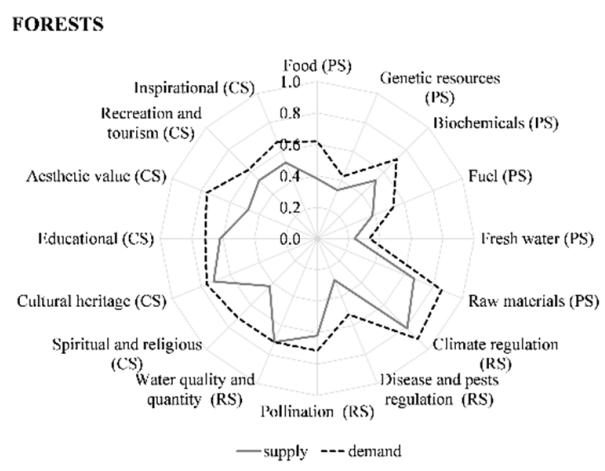

(b)

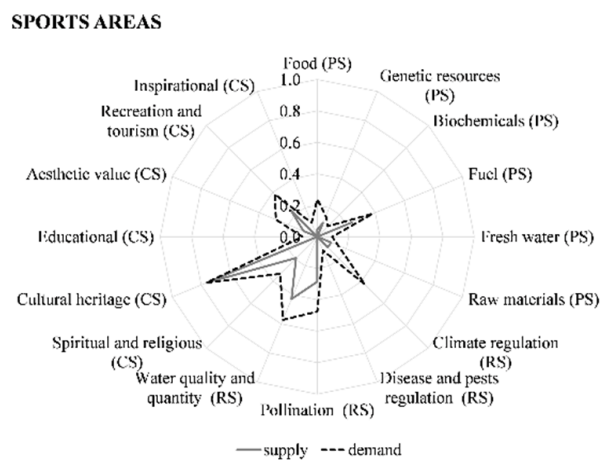

(d)

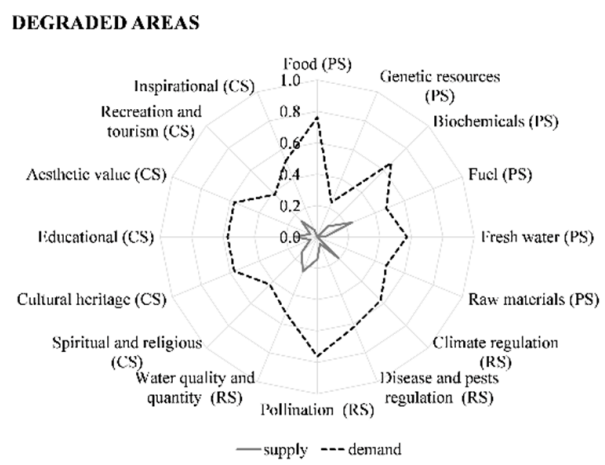

(f)

GREEN AREAS WITHIN SETTLEMENTS

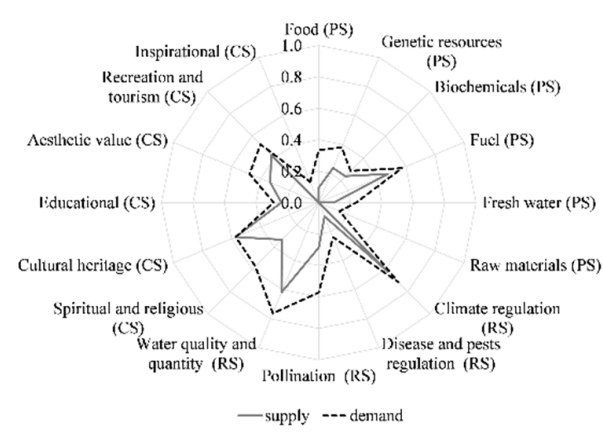

(h)

Figure 2. Relative representation of calculated links between ecosystem services contributing to human well-being components and their supply and demand through (a) parks, (b) forests, (c) allotment gardens, (d) sports areas, (e) agricultural areas, (f) degraded areas, (g) riparian vegetation, and (h) green areas within settlements in Ljubljana. PS = provisioning services, RS = regulating services, CS = cultural services. 
PARKS

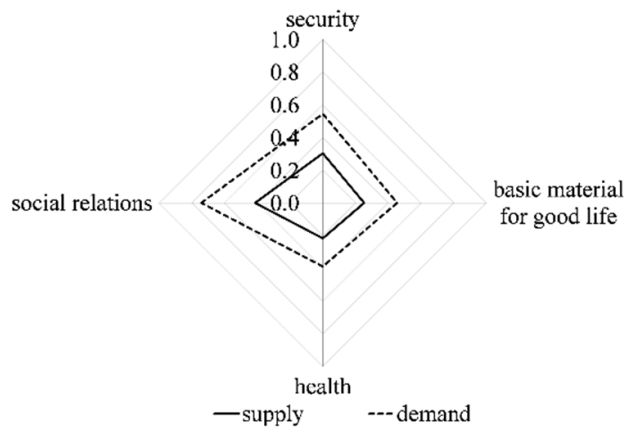

(a)

ALLOTMENT GARDENS

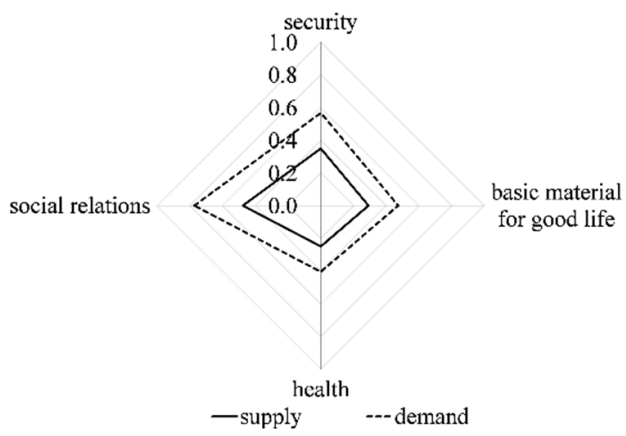

(c)

AGRICULTURAL LAND

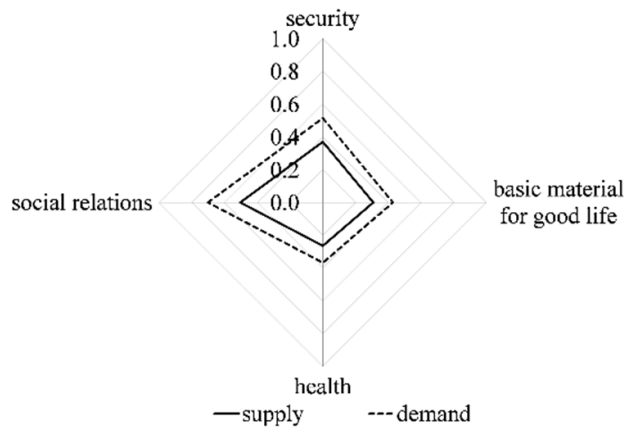

(e)

\section{RIPARIAN VEGETATION}

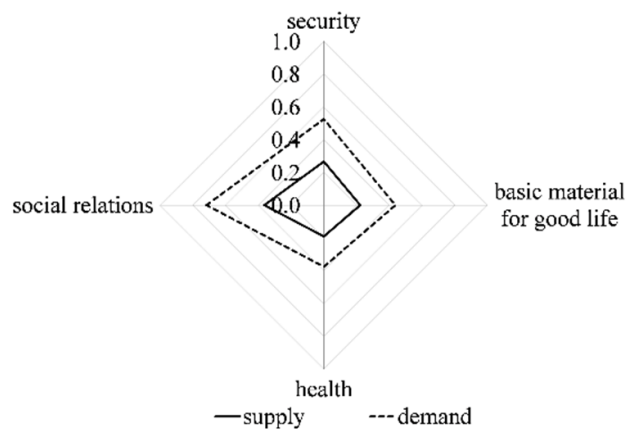

(g)

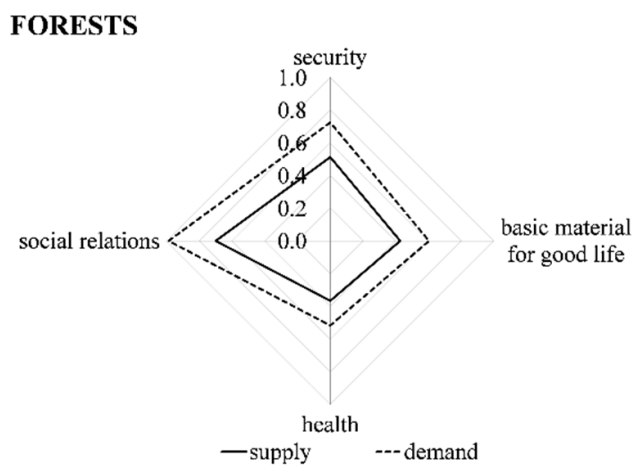

(b)

\section{SPORTS AREAS}

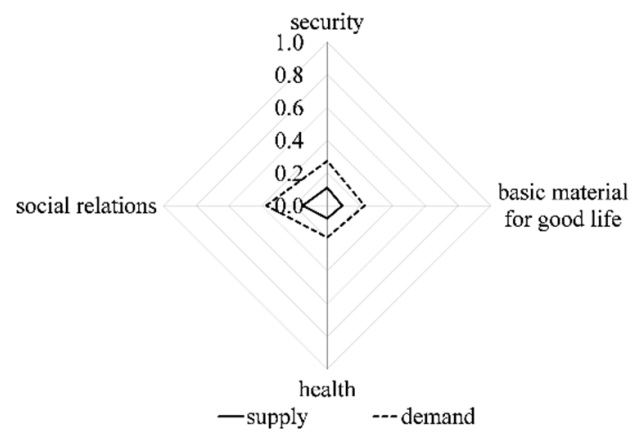

(d)

\section{DEGRADED AREAS}

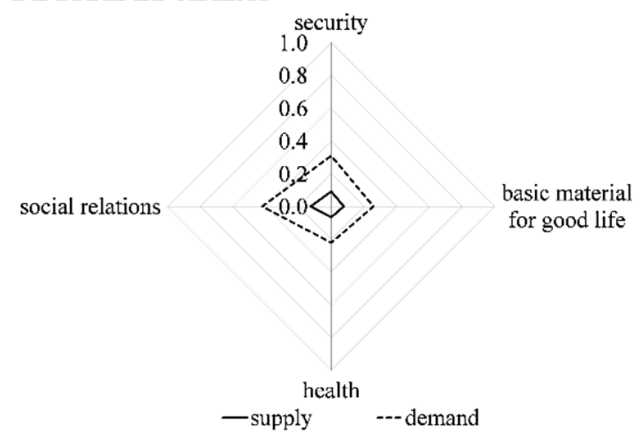

(f)

\section{GREEN AREAS WITHIN} SETTLEMENTS

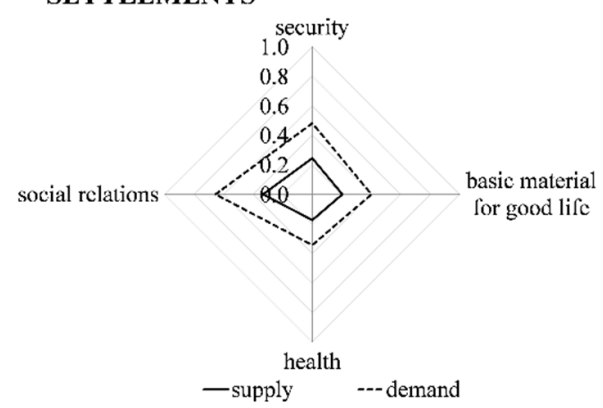

(h)

Figure 3. Relative representation of calculated links between human well-being components for (a) parks, (b) forests, (c) allotment gardens, (d) sports areas, (e) agricultural areas, (f) degraded areas, (g) riparian vegetation, and (h) green areas within settlements in Ljubljana. 


\section{Discussion}

\subsection{Demand Supply across Different Well-Being Components}

Higher ES demand over supply is not unusual in urban environments [45]. It only points to a deficit in ES supply and raises additional questions, most notably in terms of realistic stakeholder expectations, whether UGI can be enhanced to supply more ES.

It has been suggested that different ES affect WB components with varying degrees of intensity [3], with the WB component appearing to be more influenced by the social than the ecological system [46], which is consistent with the findings of this study. In addition, different perceptions of the spatial distribution of ES and demand among different stakeholder groups were observed during the ES prioritization process. These could be related to factors such as the level of knowledge and benefits that people value or need, information, mental models, the connection to the landscape and the different stakeholders' values $[8,10,47,48]$. On the other hand, Dumitru et al. [49] claim that the lack of evidence on the different uses of nature-based solutions (or in our case UGI) by different stakeholder groups makes it harder to assess differences in outcomes. Unequal distribution of UGI is the reason why assessing and evaluating actual ES perception of different stakeholder groups should be included in UGI planning and more detailed into the final design.

\subsection{Demand Supply across Different Stakeholder Groups}

The results refer to a population sample that is not statistically representative of Ljubljana residents. Nevertheless, the results could be extrapolated to the Ljubljana citizenship perceptions. In general, the results show that both the supply and demand of ES for the social relations component of WB are higher for all types of UGI. This is best illustrated by the relationships between health and sports areas and between basic materials for a good life and agricultural land, the main areas of provisioning the ES supply. These results can be attributed to the fact that the linkages between ES and social relations are weaker in the approach used in our research than for the other components of WB (column "social relations" in Table 1). Thus, the chosen approach may influence and preconcept the results, but on the other hand, other studies also show a greater need for the social ES/social WB component in urban environments $[15,50]$. It is difficult to predict a possible extrapolation of the actual results to the citizens of Ljubljana. Therefore, in the following, we compare some studies that have addressed citizens' perception of green spaces with our results.

By including Ljubljana in various European studies, we can get a more comprehensive picture of the importance of UGI in the city. In the survey conducted by Fischer et al. [51] on the importance of UGI and the related ES and activities in them, 558 Ljubljana residents participated. They named parks and forests as the most important UGI categories in the city for them and gave the greatest weight to culture ES in them. This result is consistent with ours. Another study that focused on the recreational use of parks showed that Ljubljana residents $(\mathrm{N}=543$; mainly working population, aged between $30-59$, predominantly university level education) visit parks mainly for physical use (walking, practicing sports for better health-related well-being), while social uses and nature-related uses were less represented but still essential [52]. If we look from the city policy-makers view, the city of Ljubljana attaches great importance to the preservation and improvement of the network of green spaces in the city. The city's strategic goal is to create an interconnected network of high-quality public open spaces throughout the city that are equally accessible to all residents and that are safe, recognizable, well maintained, and respectful of cultural heritage, natural resources, and the environment [38]. Fischer et al. [51] argue that biodiverse green spaces provide people in cities with an added value in relation to simply green spaces. Ljubljana residents value high biodiversity in forests and medium biodiversity in parks most in terms of liking. The likeability of green spaces is associated with recreation and other social ES demand. With further planning and improvements of the UGI, the city of Ljubljana aims to preserve the multifunctionality of its UGI areas. With this vision, the city has placed a special emphasis on creating high-quality new public UGI areas. Because of the multiple functions these areas can perform within a city, such as recreational and 
ecosystem functions, the concept of multifunctionality is an important consideration in the planning and management of these areas. These areas are often characterized by a high number of ES, such as habitat function, high recreational attractiveness, and regulating services such as air and water purification and buffer areas [38].

Moreover, van der Jagt et al. [43] explain the establishment and development of a learning alliance in Ljubljana. The process of shared learning eventually evolved into a plan to engage and support young adults, including school dropouts and the unemployed, in a project to transform an underutilized UGI area into one that provides multiple ES, beneficial for WB from leisure to sports, culture, local food production and environmental education: all that contribute to increased food self-supply, better physical and mental health, an increased feeling of guidance (security) in life and improved social relations in young adults.

\subsection{Method Application and Further Studies}

The method used facilitates a gradual exploration and incorporation of the ES concept into the planning process. Quantification of relations between WB components provides a useful way to visualize existing and expected UGI services and a shared view among stakeholders. Identifying ES linked to different types of UGI based on pictures and UGI examples from Ljubljana is the first step in informing the process.

In a social-ecological system, such as the UGI, conceptualized through a widely accepted ES concept [46], the WB component is seen as one of the most important elements of human quality of life in urban areas [53]. Therefore, the links between ES, UGI, and WB should be better understood [2,7] to support the development of ecosystem-based approaches to UGI design [4-6]. Additionally, Dumitru et al. [49] underline the lack of explicit consideration of pathways through which the ES of UGI affect different WB aspects, especially those related to human health and the social fabric. In this respect, it is crucial to evaluate public perception and demand for different ES [19], which would support the integration of the ES concept into local UGI planning in environments where this has not been the case so far.

Different levels of knowledge and values of participants imply the requirement to compare the perception of stakeholders (perceived data) with empirical data [54] by combining different decision support approaches and tools, not only to inform the planning processes [14], but also to identify possible inaccuracies [54]. In this respect, stakeholder knowledge could serve as a basis for better consideration of the ES role on WB through the UGI, which could lead to better informed urban planning processes and strategy development [10].

Application of the presented method can also be useful in supporting decision makers responsible for urban planning in a variety of ways, including the following:

- $\quad$ Awareness raising where mismatches are identified between stakeholder perception and empirical data;

- $\quad$ Identifying areas of surplus or deficit in ES supply;

- $\quad$ Identifying WB components in need of greater enhancement through ES;

- Awareness raising among stakeholders involved in the processes of considering the ES provided by UGI.

There are various methods for engaging stakeholders in assessing ES [15], and some are considered important prerequisites for implementing the ES concept by environmental institutions and decision makers [50]. The precision of evaluation methods is also increasing [55]. Compared to other methods [15], the applied method, based on the identification of the links based on the provision and demand approach, focuses more on the UGI type than on the spatial diversity of ES; therefore, it emphasizes the functionality of the links between ES and WB more than the location. For this reason, it is better suited to achieve a strategic integration of the ES concept in the planning document than a method to be used in the detailed development planning of specific UGI in the city. 


\subsection{Implication for Planning and Limitations of the Study}

The application of the theoretical method was tested in a small workshop with 21 stakeholders as part of the GREEN SURGE project [44]. We are aware that the sample might be too small for more serious ES supply-demand analyses. However, with this application, we wanted to test the applicability of the approach undertaken in our research and obtain preliminary results that can only be the basis for further research. The workshop's primary goal was to familiarize the participants with the ES concept and the possibility of introducing it into the local urban planning process.

The workshop results in Ljubljana might also be linked to inaccurate stakeholder perception; for example, a higher number of perceived ES by research organizations and youngsters might reflect their greater awareness of ES because of the activities these types of stakeholders carry out.

The approach undertaken in our research considered the feedback from WB to UGI with urban planning, similar to Burkhard et al. [18], but it was not analyzed in our study. Research focusing on the impact of changes in urban green infrastructure planning policy and projects undertaken in the light of ES demand and their impact on WB is welcome. This would close the circle and give us a better overview of all the mutual influences of the UGI-ES-WB-UGI relationship. The weights of the ES' impact on WB were taken in three stages from MEA [3]. The article also does not demonstrate the credibility of the assigned weight values. The weights may change if research shows that the ES impacts on WB components are significantly different. Additionally, the subjective perception of the components of WB $[56,57]$ is not considered in the context of UGI, which may also be an idea for further applications.

Nevertheless, the approach in our research offers to advance the scientific methods that try to link UGI with WB through ES. First, instead of only one or two, it considers several (8) types of urban green spaces. Further, instead of referring to WB as one lump phenomenon, it focuses on individual WB components and provides a weighted link between separate ES categories and individual WB components. In this respect, the approach we used could be further developed to evaluate the contribution of UGI to WB through ES using WB indicators and objectivize WB evaluation using literature review, field research, spatial analysis involving GIS and remote sensing, land use, landscape metrics, or statistical methods [26-31]. Finally, unlike most of the studies reviewed, the approach undertaken in our research focuses on a comprehensive list of ESs.

The use of the approach has implications for local planning as one of the decisionsupport tools that help us communicate with stakeholders. Engaging stakeholders in identifying gaps between the demand and supply of ES enables us to support communication with stakeholders as to what actions or priority of measures would be appropriate to increase their satisfaction with the ES, UGI, and, indirectly, WB. This helps UGI planners and managers to support citizen initiatives and guide fine UGI policy.

\section{Conclusions}

With a focus on ES in participatory decision-making processes, a common language that facilitates comparison of management alternatives was created to promote dialogue between groups with different interests and convictions and increase the likelihood that plans are acceptable to both sides. This application of participatory ES supply and demand evaluation UGI is useful for targeting spatial policies, ecosystem state awareness, priority setting, and UGI planning and management.

Stakeholders with different knowledge and values perceive the role of UGI in WB differently. In multi-stakeholder groups, such as in urban learning labs, where stakeholders from different sectors are involved, some functional linkage between ES, UGI, and WB may often not be equally recognized. To bridge the gap between stakeholder perception and knowledge in this context and to further increase stakeholder knowledge and awareness of the benefits that UGI and related ES provide to city residents, approaches that help understand and discuss the importance of UGI for WB and its potential role in urban 
planning are required. One of these approaches is the ES approach. The largest gap between ES demand and supply was identified for some social ES, such as those that are spiritual, educational, and inspirational, that are generally less considered in studies. This opens up new opportunities and the need for further research. The presented method helps acknowledge and quantify the links between ES and UGI from different stakeholder perspectives. Future research should question, with a statistically representative group of stakeholders, the set of assumed weights representing the contribution of UGI and ES to WB. The ES concept has not previously been acknowledged in Ljubljana's official space planning legislation documents. One of the workshop's important results was the contribution to introducing the expression "ecosystem service" into the spatial planning document 'Sustainable urban strategy of the City of Ljubljana': "Due to the increase of ecosystem services provided to the city's residents by green spaces in Ljubljana, the municipality will encourage participatory planning and management of the green spaces of the city, especially with residents from vulnerable groups" [35].

Author Contributions: Conceptualization, M.N., R.C.; methodology, Š.Ž., R.C. and M.N.; formal analysis, R.C., M.N. and Š.Ž.; writing—original draft preparation, M.N., R.C. and Š.Ž.; writing—review and editing, M.N., R.C.; project administration and funding acquisition, M.P. All authors have read and agreed to the published version of the manuscript.

Funding: This research was funded by the "Green Infrastructure and Urban Biodiversity for Sustainable Urban Development and the Green Economy (GREEN SURGE)", EU FP7 collaborative project, FP7-ENV.2013.6.2-5-603567.

Institutional Review Board Statement: Not applicable.

Informed Consent Statement: Not applicable.

Data Availability Statement: Not applicable.

Conflicts of Interest: The authors declare no conflict of interest.

\section{References}

1. Vierikko, K.; Elands, B.; Niemelä, J.; Andersson, E.; Buijs, A.; Fischer, L.K.; Haase, D.; Kabisch, N.; Kowarik, I.; Luz, A.C. Considering the ways biocultural diversity helps enforce the urban green infrastructure in times of urban transformation. Curr. Opin. Environ. Sustain. 2016, 22, 7-12. [CrossRef]

2. Olander, L.P.; Johnston, R.J.; Tallis, H.; Kagan, J.; Maguire, L.A.; Polasky, S.; Urban, D.; Boyd, J.; Wainger, L.; Palmer, M. Benefit relevant indicators: Ecosystem services measures that link ecological and social outcomes. Ecol. Indic. 2018, 85, 1262-1272. [CrossRef]

3. Millennium Ecosystem Assessment. Ecosystems and Human Well-Being; Island Press: Washington, DC, USA, 2005.

4. Jones, S.K.; Boundaogo, M.; DeClerck, F.A.; Estrada-Carmona, N.; Mirumachi, N.; Mulligan, M. Insights into the importance of ecosystem services to human well-being in reservoir landscapes. Ecosyst. Serv. 2019, 39, 100987. [CrossRef]

5. Hansen, R.; Frantzeskaki, N.; McPhearson, T.; Rall, E.; Kabisch, N.; Kaczorowska, A.; Kain, J.-H.; Artmann, M.; Pauleit, S. The uptake of the ecosystem services concept in planning discourses of European and American cities. Ecosyst. Serv. 2015, 12, 228-246. [CrossRef]

6. Folkersen, M.V. Ecosystem valuation: Changing discourse in a time of climate change. Ecosyst. Serv. 2018, 29, 1-12. [CrossRef]

7. Pauleit, S.; Ambrose-Oji, B.; Andersson, E.; Anton, B.; Buijs, A.; Haase, D.; Elands, B.; Hansen, R.; Kowarik, I.; Kronenberg, J. Advancing urban green infrastructure in Europe: Outcomes and reflections from the GREEN SURGE project. Urban For. Urban Green. 2019, 40, 4-16. [CrossRef]

8. Daw, T.M.; Hicks, C.C.; Brown, K.; Chaigneau, T.; Januchowski-Hartley, F.A.; Cheung, W.W.L.; Rosendo, S.; Crona, B.; Coulthard, S.; Sandbrook, C. Elasticity in ecosystem services: Exploring the variable relationship between ecosystems and human well-being. Ecol. Soc. 2016, 21, 11. [CrossRef]

9. Andersson, E.; McPhearson, T.; Kremer, P.; Gomez-Baggethun, E.; Haase, D.; Tuvendal, M.; Wurster, D. Scale and context dependence of ecosystem service providing units. Ecosyst. Serv. 2015, 12, 157-164. [CrossRef]

10. Larondelle, N.; Lauf, S. Balancing demand and supply of multiple urban ecosystem services on different spatial scales. Ecosyst. Serv. 2016, 22, 18-31. [CrossRef]

11. Mihai, B.; Reynard, E.; Werren, G.; Savulescu, I.; Sandric, I.; Chitu, Z. Impacts of tourism on geomorphological processes in the Bucegi Mountains in Romania. Geogr. Helv. 2009, 64, 134-147. [CrossRef]

12. Olya, H.G.T.; Shahmirzdi, E.K.; Alipour, H. Pro-tourism and anti-tourism community groups at a world heritage site in Turkey. Curr. Issues Tour. 2019, 22, 763-785. [CrossRef] 
13. Villamagna, A.M.; Angermeier, P.L.; Bennett, E.M. Capacity, pressure, demand, and flow: A conceptual framework for analyzing ecosystem service provision and delivery. Ecol. Complex. 2013, 15, 114-121. [CrossRef]

14. Langemeyer, J.; Gómez-Baggethun, E.; Haase, D.; Scheuer, S.; Elmqvist, T. Bridging the gap between ecosystem service assessments and land-use planning through Multi-Criteria Decision Analysis (MCDA). Environ. Sci. Policy 2016, 62, 45-56. [CrossRef]

15. Haase, D.; Larondelle, N.; Andersson, E.; Artmann, M.; Borgström, S.; Breuste, J.; Gomez-Baggethun, E.; Gren, Å.; Hamstead, Z.; Hansen, R. A quantitative review of urban ecosystem service assessments: Concepts, models, and implementation. Ambio 2014, 43, 413-433. [CrossRef] [PubMed]

16. Cotter, M.; Berkhoff, K.; Gibreel, T.; Ghorbani, A.; Golbon, R.; Nuppenau, E.-A.; Sauerborn, J. Designing a sustainable land use scenario based on a combination of ecological assessments and economic optimization. Ecol. Indic. 2014, 36, 779-787. [CrossRef]

17. Juanita, A.-D.; Ignacio, P.; Jorgelina, G.-A.; Cecilia, A.-S.; Carlos, M.; Francisco, N. Assessing the effects of past and future land cover changes in ecosystem services, disservices and biodiversity: A case study in Barranquilla Metropolitan Area (BMA), Colombia. Ecosyst. Serv. 2019, 37, 100915. [CrossRef]

18. Burkhard, B.; Kandziora, M.; Hou, Y.; Müller, F. Ecosystem service potentials, flows and demands-concepts for spatial localisation, indication and quantification. Landsc. Online 2014, 34, 1-32. [CrossRef]

19. Goldenberg, R.; Kalantari, Z.; Cvetkovic, V.; Mörtberg, U.; Deal, B.; Destouni, G. Distinction, quantification and mapping of potential and realized supply-demand of flow-dependent ecosystem services. Sci. Total Environ. 2017, 593, 599-609. [CrossRef]

20. Egerer, M.; Ordóñez, C.; Lin, B.B.; Kendal, D. Multicultural gardeners and park users benefit from and attach diverse values to urban nature spaces. Urban For. Urban Green. 2019, 46, 126445. [CrossRef]

21. Martín, E.G.; Giordano, R.; Pagano, A.; van der Keur, P.; Costa, M.M. Using a system thinking approach to assess the contribution of nature based solutions to sustainable development goals. Sci. Total Environ. 2020, 738, 139693. [CrossRef]

22. Anderson, V.; Gough, W.A.; Agic, B. Nature-Based Equity: An Assessment of the Public Health Impacts of Green Infrastructure in Ontario Canada. Int. J. Environ. Res. Public Health 2021, 18, 5763. [CrossRef] [PubMed]

23. Maghrabi, A.; Alyamani, A.; Addas, A. Exploring Pattern of Green Spaces (GSs) and Their Impact on Climatic Change Mitigation and Adaptation Strategies: Evidence from a Saudi Arabian City. Forests 2021, 12, 629. [CrossRef]

24. Stepniewska, M. The capacity of urban parks for providing regulating and cultural ecosystem services versus their social perception. Land Use Policy 2021, 111, 105778. [CrossRef]

25. van Vliet, E.; Dane, G.; Weijs-Perrée, M.; van Leeuwen, E.; van Dinter, M.; van den Berg, P.; Borgers, A.; Chamilothori, K. The influence of urban park attributes on user preferences: Evaluation of virtual parks in an online stated-choice experiment. Int. J. Environ. Res. Public Health 2021, 18, 212. [CrossRef] [PubMed]

26. Mesimäki, M.; Hauru, K.; Lehvävirta, S. Do small green roofs have the possibility to offer recreational and experiential benefits in a dense urban area? A case study in Helsinki, Finland. Urban For. Urban Green. 2019, 40, 114-124. [CrossRef]

27. Venkataramanan, V.; Packman, A.I.; Peters, D.R.; Lopez, D.; McCuskey, D.J.; McDonald, R.I.; Miller, W.M.; Young, S.L. A systematic review of the human health and social well-being outcomes of green infrastructure for stormwater and flood management. J. Environ. Manag. 2019, 246, 868-880. [CrossRef]

28. Zwierzchowska, I.; Fagiewicz, K.; Poniży, L.; Lupa, P.; Mizgajski, A. Introducing nature-based solutions into urban policy-facts and gaps. Case study of Poznań. Land Use Policy 2019, 85, 161-175. [CrossRef]

29. Battisti, L.; Pomatto, E.; Larcher, F. Assessment and Mapping Green Areas Ecosystem Services and Socio-Demographic Characteristics in Turin Neighborhoods (Italy). Forests 2020, 11, 25. [CrossRef]

30. Valente, D.; Pasimeni, M.R.; Petrosillo, I. The role of green infrastructures in Italian cities by linking natural and social capital. Ecol. Indic. 2020, 108, 105694. [CrossRef]

31. Tran, T.J.; Helmus, M.R.; Behm, J.E. Green infrastructure space and traits (GIST) model: Integrating green infrastructure spatial placement and plant traits to maximize multifunctionality. Urban For. Urban Green. 2020, 49, 126635. [CrossRef]

32. Fagerholm, N.; Eilola, S.; Arki, V. Outdoor recreation and nature's contribution to well-being in a pandemic situation-Case Turku, Finland. Urban For. Urban Green. 2021, 64, 127257. [CrossRef] [PubMed]

33. Chen, Y.; Ge, Y.; Yang, G.; Wu, Z.; Du, Y.; Mao, F.; Liu, S.; Xu, R.; Qu, Z.; Xu, B. Inequalities of urban green space area and ecosystem services along urban center-edge gradients. Landsc. Urban Plan. 2022, 217, 104266. [CrossRef]

34. Brzoska, P.; Spāge, A. From city-to site-dimension: Assessing the urban ecosystem services of different types of green infrastructure. Land 2020, 9, 150. [CrossRef]

35. The City of Ljubljana. Implementation Plan for the Sustainable Urban Strategy of the City of Ljubljana 2014-2020. Available online: https://www.ljubljana.si/sl/moja-ljubljana/urbanizem/trajnostna-urbana-strategija-mol/ (accessed on 13 February 2022).

36. Kuščer, K.; Mihalič, T. Residents' attitudes towards overtourism from the perspective of tourism impacts and cooperation-The case of Ljubljana. Sustainability 2019, 11, 1823. [CrossRef]

37. Verlič, A.; Arnberger, A.; Japelj, A.; Simončič, P.; Pirnat, J. Perceptions of recreational trail impacts on an urban forest walk: A controlled field experiment. Urban For. Urban Green. 2015, 14, 89-98. [CrossRef]

38. Nastran, M.; Regina, H. Advancing urban ecosystem governance in Ljubljana. Environ. Sci. Policy 2016, 62, 123-126. [CrossRef]

39. Pichler-Milanovič, N.; Foški, M. Green infrastructure and urban revitalisation in Central Europe: Meeting environmental and spatial challenges in the inner city of Ljubljana, Slovenia. Urbani Izziv 2015, 26, S50-S64. [CrossRef]

40. Cvejić, R.; Železnikar, Š.; Nastran, M.; Rehberger, V.; Pintar, M. Urban agriculture as a tool for facilitated urban greening of sites in transition: A case study. Urbani Izziv 2015, 26, S84-S97. [CrossRef] 
41. Svirčić Gotovac, A.; Kerbler, B. From post-socialist to sustainable: The city of Ljubljana. Sustainability 2019, 11, 7126. [CrossRef]

42. Svirčić Gotovac, A.; Zlatar Gamberožić, J.; Nikšič, M. Sodelovanje javnosti v postsocialističnih mestih med stagnacijo in napredkom. Urbani Izziv 2021, 32, 5-14. [CrossRef]

43. van der Jagt, A.P.N.; Smith, M.; Ambrose-Oji, B.; Konijnendijk, C.C.; Giannico, V.; Haase, D.; Lafortezza, R.; Nastran, M.; Pintar, M.; Železnikar, Š. Co-creating urban green infrastructure connecting people and nature: A guiding framework and approach. J. Environ. Manag. 2019, 233, 757-767. [CrossRef] [PubMed]

44. GREENSURGE Project. Green Infrastructure and Urban Biodiversity for Sustainable Urban Development and the Green Economy. FP7-ENV.2013.6.2-5-603567. Available online: https://ign.ku.dk/english/green-surge/ (accessed on 13 February 2022).

45. Burkhard, B.; Kroll, F.; Nedkov, S.; Müller, F. Mapping ecosystem service supply, demand and budgets. Ecol. Indic. 2012, 21, 17-29. [CrossRef]

46. Haines-Young, R.; Potschin, M. The Links between Biodiversity, Ecosystem Services and Human Well-Being. In Ecosystem Ecology: A New Synthesis; Cambridge University Press: Cambridge, UK, 2010; pp. 110-139.

47. Cárcamo, P.F.; Garay-Flühmann, R.; Squeo, F.A.; Gaymer, C.F. Using stakeholders' perspective of ecosystem services and biodiversity features to plan a marine protected area. Environ. Sci. Policy 2014, 40, 116-131. [CrossRef]

48. García-Nieto, A.P.; Quintas-Soriano, C.; García-Llorente, M.; Palomo, I.; Montes, C.; Martín-López, B. Collaborative mapping of ecosystem services: The role of stakeholders' profiles. Ecosyst. Serv. 2015, 13, 141-152. [CrossRef]

49. Dumitru, A.; Frantzeskaki, N.; Collier, M. Identifying principles for the design of robust impact evaluation frameworks for nature-based solutions in cities. Environ. Sci. Policy 2020, 112, 107-116. [CrossRef]

50. Hegetschweiler, K.T.; de Vries, S.; Arnberger, A.; Bell, S.; Brennan, M.; Siter, N.; Olafsson, A.S.; Voigt, A.; Hunziker, M. Linking demand and supply factors in identifying cultural ecosystem services of urban green infrastructures: A review of European studies. Urban For. Urban Green. 2017, 21, 48-59. [CrossRef]

51. Fischer, L.K.; Honold, J.; Cvejić, R.; Delshammar, T.; Hilbert, S.; Lafortezza, R.; Nastran, M.; Nielsen, A.B.; Pintar, M.; van der Jagt, A.P.N. Beyond green: Broad support for biodiversity in multicultural European cities. Glob. Environ. Chang. 2018, 49 , 35-45. [CrossRef]

52. Fischer, L.K.; Honold, J.; Botzat, A.; Brinkmeyer, D.; Cvejić, R.; Delshammar, T.; Elands, B.; Haase, D.; Kabisch, N.; Karle, S.J. Recreational ecosystem services in European cities: Sociocultural and geographical contexts matter for park use. Ecosyst. Serv. 2018, 31, 455-467. [CrossRef]

53. Kabisch, N. Ecosystem service implementation and governance challenges in urban green space planning-The case of Berlin, Germany. Land Use Policy 2015, 42, 557-567. [CrossRef]

54. Mascarenhas, A.; Ramos, T.B.; Haase, D.; Santos, R. Participatory selection of ecosystem services for spatial planning: Insights from the Lisbon Metropolitan Area, Portugal. Ecosyst. Serv. 2016, 18, 87-99. [CrossRef]

55. Gómez-Baggethun, E.; Gren, Å.; Barton, D.N.; Langemeyer, J.; McPhearson, T.; O'farrell, P.; Andersson, E.; Hamstead, Z.; Kremer, P. Urban Ecosystem Services. In Urbanization, Biodiversity and Ecosystem Services: Challenges and Opportunities; Springer: Dordrecht, The Netherlands, 2013; pp. 175-251.

56. Fagerholm, N.; Martín-López, B.; Torralba, M.; Oteros-Rozas, E.; Lechner, A.M.; Bieling, C.; Stahl Olafsson, A.; Albert, C.; Raymond, C.M.; Garcia-Martin, M. Perceived contributions of multifunctional landscapes to human well-being: Evidence from 13 European sites. People Nat. 2020, 2, 217-234. [CrossRef]

57. Maurer, M.; Zaval, L.; Orlove, B.; Moraga, V.; Culligan, P. More than nature: Linkages between well-being and greenspace influenced by a combination of elements of nature and non-nature in a New York City urban park. Urban For. Urban Green. 2021, 61, 127081. [CrossRef] 